\title{
Crecimiento, morfología y estructura urbanos en el proceso de urbanización de Zipaquirá
}

Urban growth, morphology and structure in the Zipaquirá's urbanization process

\author{
Guillermo Hernando Quintana Machado*
}

\section{Resumen}

Presenta unos acápites del trabajo de investigación denominado Análisis geográfico del proceso reciente de urbanización en el municipio de Zipaquirá. En el análisis del proceso de urbanización inciden múltiples variables. El presente escrito se centra en el crecimiento urbano desde 1970 a la fecha y en la morfología y estructura urbanas de Zipaquirá como factores incidentes que fueron y son determinantes de la actual mancha urbana del municipio. Estas variables se operacionalizarán relacionándose con las diferentes dinámicas territoriales, en torno a la estratificación socioeconómica, valor y uso del suelo.

Palabras clave: Proceso de urbanización, Crecimiento urbano, Estructura urbana, Morfología urbana, Zipaquirá.

* Ingeniero Catastral y Geodesta. Esp. en Sistemas de Información Geográfica. M.Sc. en Geografía.

Perspectiva Geográfica Núm. 1 1, 2005 197 


\section{Abstract}

These are fragments of the investigation called "Geographic analysis of the Zipaquirá's municipally urbanization recent process", in which multiple variables have incidence. The present text focus the urban growth since 1970 to the date, and the Zipaquirá morphology and urban structure, as factors which were and are determinants in the actual urban city development. These variables are operationally related with the different territorial dynamics, around the social economical situation, and around the land value and way of use.

Key words: Urbanization process, Urban growth, Urban structure, Urban morphology, Zipaquirá.

198 Guillermo Hernando Quintana Machado 


\section{Introducción}

El análisis del proceso de urbanización de un Centro Funcional Principal y Polo de Desarrollo Subregional de intensa actividad, como es Zipaquirá, cobra gran importancia en el contexto local y regional alrededor de Bogotá. Los procesos de urbanización de tipo local-municipal hacen parte de un contexto amplio territorial y dinamizan en doble vía la estructuración de las fuerzas territoriales.

El municipio de Zipaquirá se encuentra al norte de Bogotá, aproximadamente a $50 \mathrm{~km}$; limita por el norte con los municipios de Cogua y Nemocón, por el oriente con el municipio de Tocancipá, por el sur con Cajicá y Tabio y por el occidente con Pacho y Subachoque. Hace parte del tercer anillo metropolitano de la sabana de Bogotá (Misión Siglo XXI, 1995: 43). Zipaquirá, por la importancia que tiene en el ámbito regional-provincial y por su capacidad de polarizar gran cantidad de población en su entorno -aparte de comandar la asociación de municipios Asocentro-, se consideró un municipio con una dinámica propia, digna de ser analizada en una investigación a nivel de trabajo de grado para maestría.

El presente artículo se centra en analizar e interpretar el proceso de urbanización del municipio Zipaquirá, partiendo de una evolución histórica comprendida desde el inicio de la década de los setenta hasta la fecha; para el efecto, se abordan variables como crecimiento urbano y morfología y estructura urbanas, entre otras. En este análisis se utilizaron índices para la caracterización de la estructura urbana, técnicas de fotointerpretación, análisis variados en Sistemas de Información Geográfica y algunos criterios de clasificación de variables urbanas; estos procedimientos se explicarán en la parte metodológica.

Cabe aclarar que la investigación abordada es básicamente descriptiva y que además se caracteriza por el procesamiento y análisis técnico de información primaria y secundaria, procurando plantear resultados que aporten al conocimiento del territorio municipal de Zipaquirá.

\section{El proceso de urbanización}

Según Vinuesa y Vidal (1991), en términos genéricos urbanizar es hacer urbano, es convertir en poblado una porción de terreno o prepararlo para ello, abriendo calles o dotándolas de luz, pavimento y demás servicios urbanos. De ello cabe interpretar que los procesos de urbanización son series de transformaciones que van teniendo lugar a lo largo del tiempo y mediante las cuales algo que no lo era adquiere el carácter de urbano.

Según Lampard, citado por Carter (1972), hay "tres conceptos de urbanización gozando de crédito en las ciencias sociales: el conductista, el estructural y el demográfico". El 
primero se refiere a la experiencia del individuo a través del tiempo y las normas de conducta; el segundo concierne a las actividades de toda la población y depende fundamentalmente de los cambios de la estructura económica, y el tercero considera el proceso, primordialmente, como de concentración de población.

Para el IGAC (1990), la urbanización se puede definir como un proceso de transformación de una sociedad rural a urbana, en el que se establecen jerarquías entre las diferentes aglomeraciones urbanas, dependiendo de la manera en que las ciudades obtienen mayor importancia con relación a las demás.

\section{Morfología urbana}

Según Estébanez y otros (1995), la morfología urbana a través de la historia ha tenido diferentes acepciones y finalidades; inicialmente se utilizó para explicar los procesos comportamentales de los habitantes de la ciudad, al considerar la delimitación de subáreas con elementos homogéneos morfológicos comunes. Durante mucho tiempo "el emplazamiento" y "la situación" tuvieron gran importancia porque se consideró que explicaban el desarrollo de la ciudad, así como su morfología y actividades económicas.

Posteriormente se relacionó la morfología del espacio urbano edificado, intentando descubrir las diferentes etapas en su construcción y señalando zonas diferenciadas que constituían grupos sociales distintos. En la década de los sesenta se hicieron estudios de percepción del paisaje urbano a diferentes escalas urbanas, en el decenio siguiente se aborda la morfología y la estructura urbanas desde un enfoque prospectivo.

\section{Componentes básicos de la morfología urbana}

Sin duda alguna, las condiciones del medio natural son un componente básico de la morfología urbana; según los mismos autores, el marco natural, aunque no tenga la importancia que se creyó anteriormente, tiene un carácter determinante y es un elemento fundamental del origen y posterior desarrollo de las ciudades, entendidas como un hecho histórico y geográfico, constituyendo la expresión material de un paisaje creado. En este sentido se hace necesario estudiar dos conceptos básicos: "el emplazamiento" y "la situación". "La ciudad, desde su origen, al desarrollarse y parcelar terrenos para la edificación tuvo que tener en cuenta los elementos del territorio, la topografía y convertir estos componentes en elementos esenciales del espacio urbano" (Estébanez, 1995: 473).

Emplazamiento: es el espacio concreto y material sobre el que se asienta la ciudad, es la topografía, el soporte físico que, desde el momento de la fundación y a lo largo de evolución, va a condicionar en parte el paisaje urbano y su desarrollo espacial. La elección del emplazamiento 
depende de la función dominante de la ciudad en el momento de su fundación, y de las características del medio físico.

Situación: es el entorno geográfico en la que la ciudad se encuadra y con relación al que se organiza. La situación se refiere a las grandes vías de comunicación, a los grandes espacios económicos. Desde el punto de vista de la situación se puede hablar de ciudades con situación de encrucijada, ciudades en la confluencia de grandes vías de comunicación: ríos, carreteras o ferrocarriles..." (Estébanez, 1995: 474).

El Plano. Para Zárate (1992), el plano es el resultado de la combinación sobre el espacio de la ciudad, a través del tiempo, de superficies libres (calles, parques y jardines, plazas, lugares de aparcamiento, etc.) y también de las superficies construidas. Según Estébanez y otros, el plano puede definirse como la plasmación de la disposición y combinación de los espacios no edificados o públicos, agregando a los elementos descritos en la definición anterior los solares edificados o edificables o espacio privado.

A continuación se definirán los diferentes enfoques de análisis del plano urbano y su respectiva clasificación:

\section{Enfoques de análisis de forma}

- Plano en cuadrícula o damero: es un plano ortogonal, donde las calles se cortan en ángulo recto. Es el más extendido, puesto que se ha aplicado a todas las épocas desde la antigüedad, sobre todo para fundar ciudades coloniales.

- Plano radioconcéntrico: está formado por calles que parten del centro a modo de radios y otras que forman círculos concéntricos que cortan perpendicularmente las calles radiales.

- Plano irregular: no obedece a un plan o proyecto previo, sino que es el resultado de un crecimiento espontáneo.

\section{Enfoques de análisis histórico}

- Según Zárate (1992: 44), también existen enfoques que analizan el plano en torno a la historia de la ciudad. Parten de la idea de que el plano actual es fruto de un proceso de expansión a lo largo del tiempo, en el que han sucedido etapas de crecimiento y estancamiento, a cada una de las cuales corresponde un determinado modelo de ordenación del espacio.

\section{Enfoques de análisis reciente}

En estudios recientes se ha intentado interpretar el plano en términos de análisis de redes, y la consideración del plano como el producto de la influencia de una multitud de variables.

\section{Factores que modelan el plano}

Para Zárate (1992), unas de las principales variables, o factores, que permiten explicar la formación del plano son el relieve, los ríos y las carreteras. 
Según Estébanez y otros (1995), el mayor esfuerzo por generalizar los componentes del paisaje urbano se debe a Conzen (1960), que llegó a las siguientes generalizaciones:

- Los componentes del paisaje urbano no tienen todos la misma estabilidad; el plano y los edificios son más duraderos que la función.

- En el plano de la ciudad existen dos elementos muy significativos: el cinturón de expansión y las líneas de fijación.

Las líneas de fijación se interpretan como los elementos estructurantes del plano que actúan como obstáculos o barreras; pueden ser elementos físicos, humanos o incluso aspectos no visibles en el territorio, como la estructura de la propiedad. Las líneas de fijación pueden ceder en un momento determinado ante la presión constructora, creando un cinturón de expansión que a veces se mantiene en el plano durante un largo lapso, con un predominio de solares edificables sobre el espacio edificado.

\section{Las formas de crecimiento urbano}

Dentro del espacio se pueden encontrar múltiples formas de crecimiento urbano, como son:

- La parcelación: morfología de la ocupación del suelo.

- La urbanización: construcción de la infraestructura urbana.
- La edificación: construcción de los edificios según tipologías edificatorias.

Se podrá distinguir, inicialmente, en las formas de crecimiento urbano, aquellas que han sido resultado de un planeamiento urbano previo y las que se han desarrollado al margen del planeamiento. La secuencia más habitual en el crecimiento urbano con planeamiento es la siguiente: parcelación - urbanización - edificación. Dentro de la segunda categoría hay formas de crecimiento que pueden integrarse posteriormente en el planeamiento vigente, mientras que otras son totalmente irrecuperables. En la ciudad actual se encontrará una variada combinación de diversas formas de crecimiento urbano.

\section{Unidades de construcción y creci- miento urbano}

En este ítem se van a describir los diferentes tipos de construcción y crecimiento urbano, con sus respectivas categorías según Colciencias-CEDE (1999).

Los tipos básicos están constituidos por las siguientes categorías:

Manzana tradicional: es la unidad mínima de la retícula en damero, que constituye el trazado fundacional heredado del urbanismo de los periodos de la Conquista y la Colonia españolas. Es un cuadrado de área y proporciones con una gran homogeneidad: desde $80 \times 80 \mathrm{~m}$ hasta $100 \mathrm{x}$

202 Guillermo Hernando Quintana Machado 
100 m, aproximadamente. La sucesión de manzanas determina la morfología de retícula en damero del trazado urbano; la proporción y tamaño de la manzana define la división predial en su interior, que hoy por hoy es de una marcada irregularidad y heterogeneidad en el tamaño y forma de los lotes, producto de las sucesivas subdivisiones a lo largo del tiempo.

Variante de la manzana tradicional: es la unidad mínima de una retícula cuadrangular o rectangular, generalmente fragmentaria e irregular, que constituye casi siempre la continuación inmediata de la retícula en damero. Se desarrolla en la primera mitad del siglo $\mathrm{xx}$, particularmente entre los años cuarenta y cincuenta, décadas en las que la mayoría de los núcleos urbanos sabaneros empiezan a crecer más allá de las fronteras coloniales.

La variante de la manzana tradicional, cuadrada o rectangular, tiene dimensiones diversas, que generalmente no sobrepasan las de la manzana tradicional; su forma condiciona la división de los predios en su interior, aunque hay un claro intento de regularización del tamaño y forma de los lotes. La sucesión de manzanas -generalmente en pequeña escala-, determina la morfología de retícula cuadrangular, rectangular o irregular que adquiere el trazado urbano.

Prebarra: es la unidad mínima de retículas rectangulares de tipo fragmentario, que generalmente le da continuidad a la retícula de la manzana variante de la tradicional. Se desarrolla durante las décadas de los años sesenta, setenta y ochenta. También puede ser uno de los elementos en el interior de un circuito urbano. La forma y proporciones de la prebarra, generalmente entre 80 y $100 \mathrm{~m}$ de largo por 40 y $60 \mathrm{~m}$ de ancho -aun cuando ofrece mayores variaciones-, presenta simultáneamente dos racionalidades: i) una de tipo urbanístico, en la que la prebarra posibilita dar continuidad a la retícula en damero o a la retícula de la manzana variante de la tradicional, mediante la conservación en uno de sus costados de proporciones parecidas a las de estas retículas $(80-100 \mathrm{~m})$, y ii) otra de tipo inmobiliario, que se traduce en una división predial en su interior, basada en la repetición de lotes modulados, loteo en serie, dispuestos en doble crujía, con alguna alteración de la disposición y tamaño de los lotes que se localizan en sus extremos.

Barra: es una unidad que presenta muy diversas escalas de agrupación, desde la barra individual hasta territorios que abarcan 50 hectáreas; por esta razón se asocia a diferentes tipos intermedios -retículas rectangulares de tipo fragmentario, racimos y circuitos-. $\mathrm{Su}$ desarrollo se evidencia desde los años setenta, pero adquiere claro predominio en la década de los noventa. Emparentada con la "prebarra", lleva a extremos la racionalidad inmobiliaria y abandona el interés por dar continuidad a los trazados urbanos de periodos anteriores -manzana 
fundacional, variantes de esta y "prebarra"-. El tamaño del lote en serie se reduce a dimensiones mínimas (12 x $6 \mathrm{~m}$ ) y su repetición puede adquirir grandes escalas, generando "barras" de proporciones poco adecuadas desde el punto de vista del trazado urbano.

Los tipos intermedios o formas que adquiere la agregación o asociación de unidades básicas, las constituyen:

Retícula en damero (manzana tradicional): su unidad básica es la manzana fundacional. Este trazado, que corresponde al del centro tradicional de la mayoría de las cabeceras urbanas de la sabana de Bogotá, es una retícula de tipo ortogonal que alberga en su centro una plaza central -plaza mayor- y que dependiendo de la extensión puede involucrar equipamientos básicos. La geometría de su trazado constituye un sistema abierto, que posibilita su prolongación continua en las cuatro direcciones. A partir del estudio realizado por Colciencias-CEDE, se afirma que es un tipo de trazado y una forma de crecimiento urbano que condiciona de manera importante características de compacidad, continuidad, unidad y estructuración del espacio urbano.

Fragmentos de retículas cuadrangulares y rectangulares (manzana variante de la manzana tradicional, prebarra, barra): la designación como fragmento establece un condicionamiento inicial; este tipo de retículas, en el caso de las cabeceras urbanas de la región (alrededor de Bogotá), no han producido áreas urbanas con suficientes niveles de unidad y estructuración urbanística. Los fragmentos de retícula a partir de variantes de la manzana tradicional, por las características de este tipo de manzana, posibilitan en términos generales la continuidad de la retícula en damero; sin embargo, una cierta irregularidad en la forma y proporciones de las manzanas, así como una disposición de ellas de manera un tanto aleatoria, empiezan a evidenciar condiciones de discontinuidad y dislocación de la retícula y el trazado urbano.

Circuitos urbanos (vivienda predio a predio, manzana variante de la manzana tradicional, prebarra, barra, racimo urbano): constituyen una forma de crecimiento urbano a la que no le corresponde un tipo básico específico; una de sus características particulares la constituye la heterogeneidad de unidades urbanas básicas que asocia vivienda predio a predio, manzana variante de la manzana tradicional, prebarra, barra y racimo urbano; su estructura interior está conformada por trazados fragmentarios y discontinuos, del tipo racimo, que admiten otras formas de crecimiento urbano -prebarras, barras, conjuntos cerrados, vivienda unifamiliar-; presentan diversos grados de consolidación, desde incipiente -con una alta proporción de lotes vacíos y baja densidad de ocupación - hasta consolidado o colmatado, en el que la fragmentación y discontinuidad de su estructura son evidentes. 
Racimos urbanos (vivienda predio a predio, barra): es una forma de ocupación del suelo de origen y carácter típicamente rural, que se ha adoptado al crecimiento urbano en estrecha asociación con el circuito; en la generalidad de los casos constituye el fragmento básico a partir del cual se construye el trazado interno de este. Se caracteriza porque a lo largo de una vía se desprenden vías menores, que no pretenden construir de manera formal un trazado y que se disponen a la manera de las ramas de un árbol, con bifurcaciones cada vez menores; a estas vías se "cuelgan" fracciones de áreas urbanas -viviendas predio a predio, prebarras, barras, conjuntos cerrados- en trazados que constituyen fragmentos $y$ no unidades distinguibles. Cuando su presencia no está asociada a circuitos urbanos, generalmente se localizan en las áreas urbanas periféricas, a lo largo de vías veredales, conformando territorios de baja densidad de ocupación, difusamente delimitados y con características marcadamente rurales.

\section{Estructura urbana}

Según Zárate (1992), se entiende por estructura urbana la especialización del suelo de la ciudad en zonas diferenciadas, las actividades predominantes en ellas y sus características sociodemográficas.

\section{Modelos de análisis de la estructura urbana}

De acuerdo con Zárate (1992: 107), durante mucho tiempo la estructura de cada ciudad fue considerada caso único y excepcional. Sin embargo, las coincidencias en la distribución de las distintas zonas y áreas del suelo, conforme a una serie de factores, entre los que destacan la accesibilidad, el valor del suelo y el modo de efectuarse la expansión urbana, han conducido a la elaboración de diversas teorías o modelos.

En este sentido, Gómez (1990: 218) dice: los llamados modelos clásicos de usos urbanos del suelo han tenido un impacto considerable en la literatura de estudios urbanos; se destacan los trabajos de un grupo de sociólogos urbanos de Chicago, quienes plantean las primeras teorías generales sobre el comportamiento de la estructura urbana de las ciudades norteamericanas hace 50 años; los tres modelos propuestos son: modelo zonal concéntrico, modelo de los sectores y modelo de los núcleos múltiples. A continuación se desarrollan estos modelos de análisis sobre la estructura urbana según el mismo autor:

- Modelo zonal concéntrico: es el más conocido; fue expuesto por Ernest W. Burgess en 1923 y se le conoce con el nombre de "Teoría concéntrica" o de las "Áreas concéntricas". Dicho modelo se basa en la noción de que el desarrollo de la ciudad tiene lugar hacia afuera, a partir de su área central; formando una serie de anillos o áreas concéntricas.

- Modelo de los sectores: propuesto por primera vez en 1939 por el 
economista norteamericano H. Hoyt, quien enfocó su teoría sobre vivienda y rentabilidad; él obtuvo datos y mapas de manzanas sobre la rentabilidad en 142 ciudades americanas; de dicha investigación práctica salió su modelo sectorial, que tomó la forma de: un primer anillo, donde se encuentra el distrito central de negocios, con una serie de sectores que emanan o nacen del primero hasta la periferia.

- Modelo de los núcleos múltiples: este tercer modelo clásico fue descrito en 1945 por C. D. Harris y E. L. Ullman con el nombre de "Teoría de los núcleos múltiples". Según dicha teoría, las ciudades tienen una estructura esencialmente celular, en la cual los diferentes tipos de utilización del suelo se han desarrollado alrededor de ciertos puntos de crecimiento o núcleos, situados en el interior del área urbana.

\section{Las diferentes áreas urbanas}

El sector central (CBD): Según Estébanez y otros (1995), el centro de las ciudades de mediano y gran tamaño en los países industrializados presenta unos rasgos de usos del suelo, funciones y actividades económicas que lo convierten en un espacio destacado y atrayente. Los geógrafos americanos denominan este sector con el nombre de Central Business District (CBD) y ha sido definido como el sector de una ciudad donde el comercio al por menor de bienes y servicios y la presencia de actividades administrativas y financieras con fines lucrativos dominan la escena y dan carácter a los usos del suelo. Sus principales características, según Zárate (1992), son: buena accesibilidad, alta concentración de tráfico de vehículos y de peatones, reducida población residencial, escasa actividad industrial, alto dinamismo y movilidad.

La zona de transición: para Zárate (1992), al lado del borde exterior del CBD se encuentra lo que los geógrafos americanos denominan zona de transición, que se extiende entre el centro de negocios y las áreas residenciales interiores y está caracterizada por la gran diversidad de usos del suelo y por la dinámica en los cambios de actividades y población.

Las áreas residenciales: sobre las áreas residenciales siempre ha existido gran interés de los investigadores, porque ocupan gran extensión de la ciudad y generalmente se segregan de las demás actividades del suelo urbano. Estas áreas se pueden analizar desde dos enfoques: el de la morfología y el de la composición social de sus habitantes. Según Zárate (1992: 79), a un área residencial ocupada por determinado estrato social le corresponde una edificación de características concretas. Un fenómeno que ha existido siempre es la diferenciación residencial, resultado de la interacción de varios factores sociales, económicos y culturales, entre otros.

Las áreas industriales: la localización de la industria en la ciudad obedece a una 
serie de variables que contribuyen a su desarrollo, como el mercado urbano, la concentración de los sistemas de transporte, mano de obra, economías de aglomeración, decisiones directivas, etc. Las industrias se distribuyen en la ciudad de acuerdo con un modelo polinucleado, conformado por diversas áreas, donde los usos industriales son predominantes o exclusivos.

Las áreas comerciales: el desarrollo de la actividad comercial caracteriza la ciudad en los siguientes aspectos: comercios propiamente dichos, comercios en transformación y servicios. Exceptuando las ciudades industriales, el comercio es el que genera más empleo.

\section{Ubicación general del área de estudio}

La zona de estudio se ubica en Colombia, en su región central, en el departamento de Cundinamarca, específicamente es el área urbana consolidada y centros poblados del municipio de Zipaquirá; la localización general de la zona de estudio se puede apreciar en el mapa 1: delimitación de la zona de estudio. El espacio por estudiar tiene un área de $702,2^{*}$ ha, ubicadas entre las coordenadas planas Este: $1.006 .300 \mathrm{mE}$ y $1.013 .700 \mathrm{mE}$, Norte: $1.094 .900 \mathrm{mN}$ y $1.049 .600 \mathrm{mN}$. En la zona de estudio hay diferentes clasificaciones del suelo, como se puede observar en el mapa 1; existe suelo urbano, suelo de expansión urbana y centros poblados rurales. 


\section{Mapa 1}

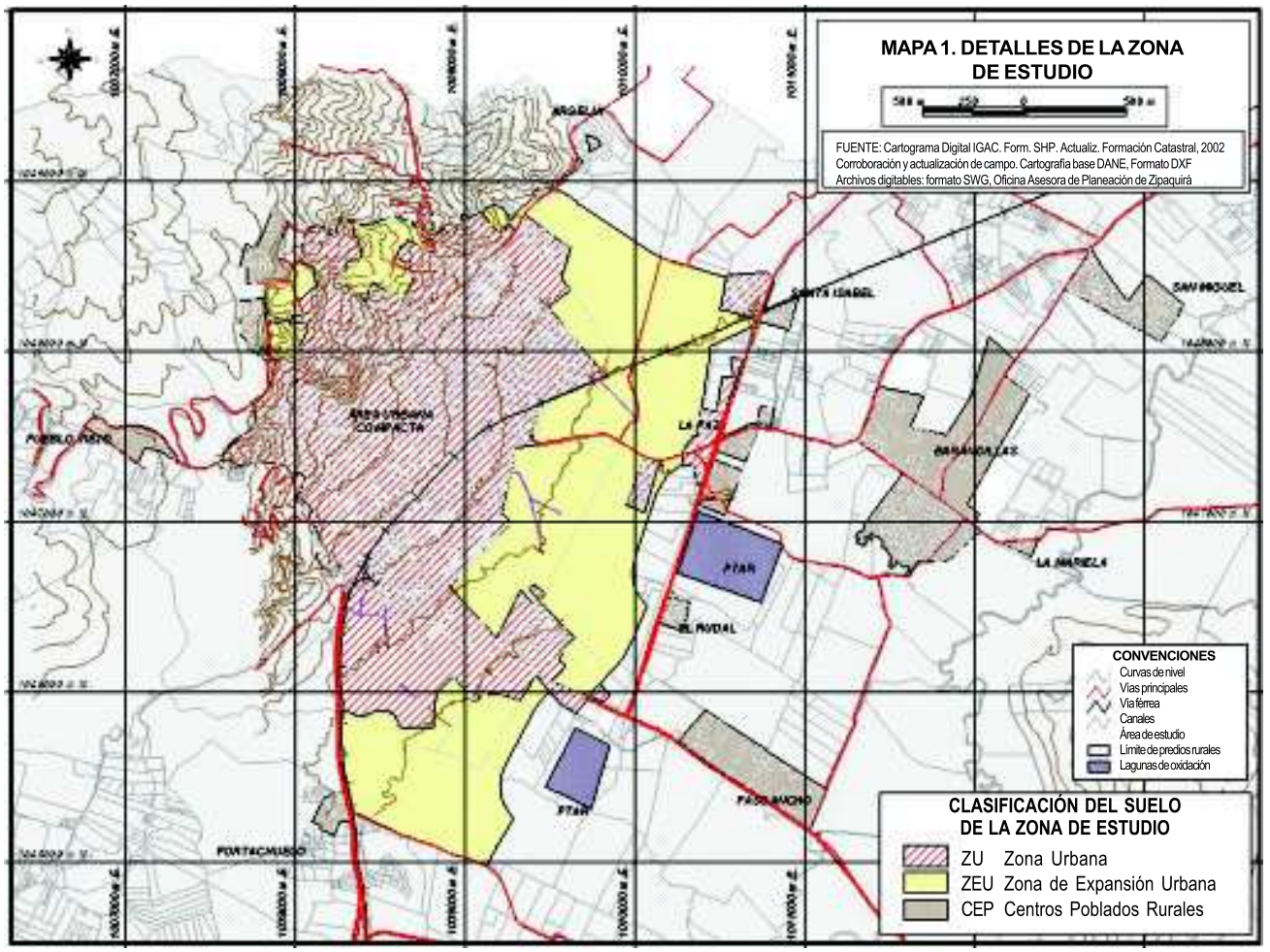

* El área de la zona de estudio se definió cartográficamente tomando como base la información suministrada por el Instituto Geográfico Agustín Codazzi al municipio de Zipaquirá, producto del proceso de Actualización de la Formación Catastral vigencia 2002. Archivos en formato digital, Shapefile (SHP), según el Modelo de Datos Urbano, Catálogo de Objetos CO-U, y Catálogo de Símbolos CS-2000, correspondientes al tema de Catastro (2000), grupo Áreas Catastrales, Terreno del Predio (2111), de acuerdo con la clasificación de elementos que maneja el IGAC.

208 Guillermo Hernando Quintana Machado 


\section{Aspectos metodológicos}

Definición del tipo de investigación: explicativa.

Definición del tema de investigación: definición del problema de investigación, planteamiento de objetivos, re- visión de estudios o casos similares anteriores y definición del marco conceptual.

Definición de variables: en los cuadros 1,2 y 3 se plantean las variables utilizadas para cumplir los objetivos de la investigación.

\section{Cuadro 1. Definición de variables}

\begin{tabular}{|l|}
\hline \multicolumn{1}{|c|}{ VARIABLES } \\
\hline $\begin{array}{l}\text { 1. Crecimiento urbano: el crecimiento urbano se interpreta como el aumento de la } \\
\text { mancha urbana, la adición de área construida en cada período de tiempo, que se } \\
\text { registra mediante la fotointerpretación de aerofotografías. }\end{array}$ \\
\hline $\begin{array}{l}\text { 2. Morfología urbana: la morfología de la ciudad es el resultado de la combinación de } \\
\text { tres elementos: el plano, la edificación y los usos del suelo, sometidos a un ritmo de } \\
\text { cambio diferente. }\end{array}$ \\
$\begin{array}{l}\text { 3. Estructura urbana: se interpreta como la especialización del suelo de la ciudad en } \\
\text { zonas diferenciadas por sus características demográficas, sociales y por las activida- } \\
\text { des dominantes en ellas. }\end{array}$ \\
\hline
\end{tabular}

Cuadro 2. Variables e indicadores del problema

\begin{tabular}{|l|l|}
\hline VARIABLES & \multicolumn{1}{|c|}{ INDICADORES } \\
\hline 1. Crecimiento urbano & 1.1 Licencias de construcción \\
\hline & 1.2 Mancha urbana \\
\hline & 1.3 Número de predios \\
\hline 2. Morfología urbana & 2.1 Situación \\
\hline & 2.2 Emplazamiento \\
\hline & 2.3 Trazado (manzaneo) \\
\hline & 2.4 Usos del suelo urbano \\
\hline & 2.5 Tenencia de la tierra \\
\hline 3. Estructura urbana & 3.1 Posiciones relativas de los usos \\
\hline & 3.2 Estrato socioeconómico \\
\hline
\end{tabular}

Fuente: Esta investigación. 


\section{Cuadro 3. Definición conceptual y operacional de indicadores}

\section{INDICADORES}

1.1 Licencias de construcción: es el acto por el cual se autoriza, a solicitud del interesado, la adecuación de terrenos o la realización de obras.

Operacionalización (cuantitativa): se mide por el número de licencias de construcción otorgadas por la administración municipal en cada año desde 1970.

1.2 Mancha urbana: se entiende como el área construida de la zona de estudio, obtenida mediante fotointerpretación de las aerofotografías y de corroboración en campo para el periodo actual. Operacionalización (cuantitativa): se mide por la variación de hectáreas (ha) por período de tiempo.

1.3 Número de predios: es el número de predios según los reportes anuales del IGAC (estadísticas catastrales - distribución por rangos de superficie).

Operacionalización (cuantitativa): se mide por el número de predios por cada año del periodo analizado.

2.1 Situación: es el entorno geográfico en la que la ciudad se encuadra y con relación al que se organiza, se evalúan vías y la relativa cercanía a Bogotá.

Operacionalización (cualitativa): descripción de su interconexión vial y su relación con el núcleo metropolitano.

2.2 Emplazamiento: es el espacio concreto y material sobre el que se asienta la ciudad, es la topografía, el soporte físico que condiciona el paisaje urbano y su desarrollo espacial.

Operacionalización (cualitativa): descripción de las características del medio físico.

2.3 Trazado (manzaneo): es la característica morfológica de la unidad de construcción, que establece una forma característica al espacio urbano.

Operacionalización (cualitativa): se clasifica cada zona del área de estudio, de acuerdo con el tipo de unidad de construcción.

2.4 Usos del suelo urbano: se interpreta como las diferentes utilizaciones que se hacen del espacio en función de las necesidades y actividades de la población.

Operacionalización (cualitativa): clasificación del uso del suelo a nivel predial en residencial, institucional, comercial e industrial.

2.5 Tenencia de la tierra: es el derecho jurídico o de hecho de ejercer propiedad o posesión sobre un predio.

Operacionalización (cuantitativa): se mide por la relación entre área o terreno por propietario.

3.1 Posiciones relativas de los usos: es la disposición de las zonas de usos dentro de la ciudad. Operacionalización (cualitativa): es la descripción de la ubicación relativa de las determinadas zonas de usos en la ciudad.

3.2 Estrato socioeconómico: es una clasificación de la población por grupos de acuerdo a condiciones socioeconómicas, determinada con base en la vivienda.

Operacionalización (cualitativa): se mide de acuerdo a la clasificación determinada por el DNP, para este estudio se dan los estratos 1, 2, 3 y 4 (bajo-bajo, bajo, medio, medio-alto).

Fuente: Esta investigación.

210 Guillermo Hernando Quintana Machado 


\section{Recopilación de información}

Se recopiló la información secundaria existente sobre el tema en las instituciones respectivas así; DANE, IGAC, INVIAS, DNP, Catastro Nacional, etc. Entidades que se encuentran en Bogotá y en Zipaquirá. Posteriormente se validó y organizó la información recopilada y se hizo el levantamiento y recolección de información primaria.

Utilización de la herramienta, sistema de información geográfica

Se utilizó el software ArcView Demo 3.1 para el procesamiento de la información cartográfica, análisis y geoprocesamiento digital de datos, operaciones de superposición y obtención de reportes.

\section{Análisis del proceso de crecimiento y expansión urbana en la zona de estudio en las tres últimas décadas}

Para facilitar el análisis de la zona de estudio se tomará para este capítulo la información de la división políticoadministrativa urbana de barrios, urbanizaciones, comunas y centros poblados rurales actualizada al año 2002 mediante trabajo de campo, ajustada a la información predial producto de la actualización de la formación catastral con vigencia de enero de 2002. El desarrollo del área construida en la zona de estudio se analizará según la fotointerpretación de las aerofotografías de los años 1960, 1977, 1984, 1988, 1992, 1997 y 2002. En el mapa 2 se puede observar la evolución del área construida en cada período; los resultados obtenidos de la fotointer-pretación se armonizaron con la información cartográfica IGAC a nivel de predio. 


\section{Mapa 2}

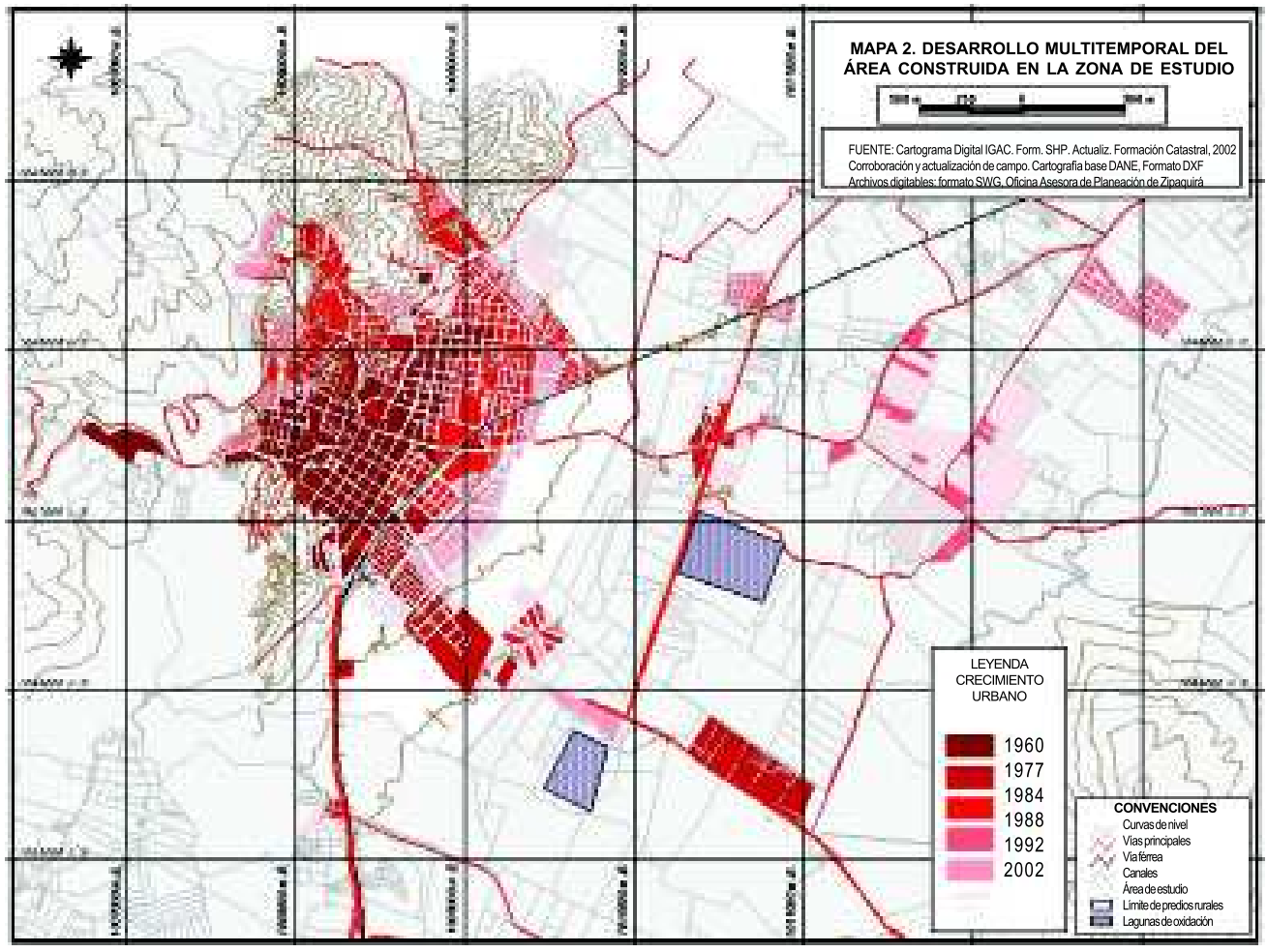

La información de licencias de construcción, suministrada por la Oficina Asesora de Planeación Municipal de Zipaquirá, se confrontó con los reportes del Instituto Geográfico Agustín Codazzi de estadísticas catastrales para predios urbanos y rurales de Zipaquirá; esto a la vez se confrontó con las tasas de crecimiento de la mancha urbana extraída de la fotointerpretación (ver figura 1).

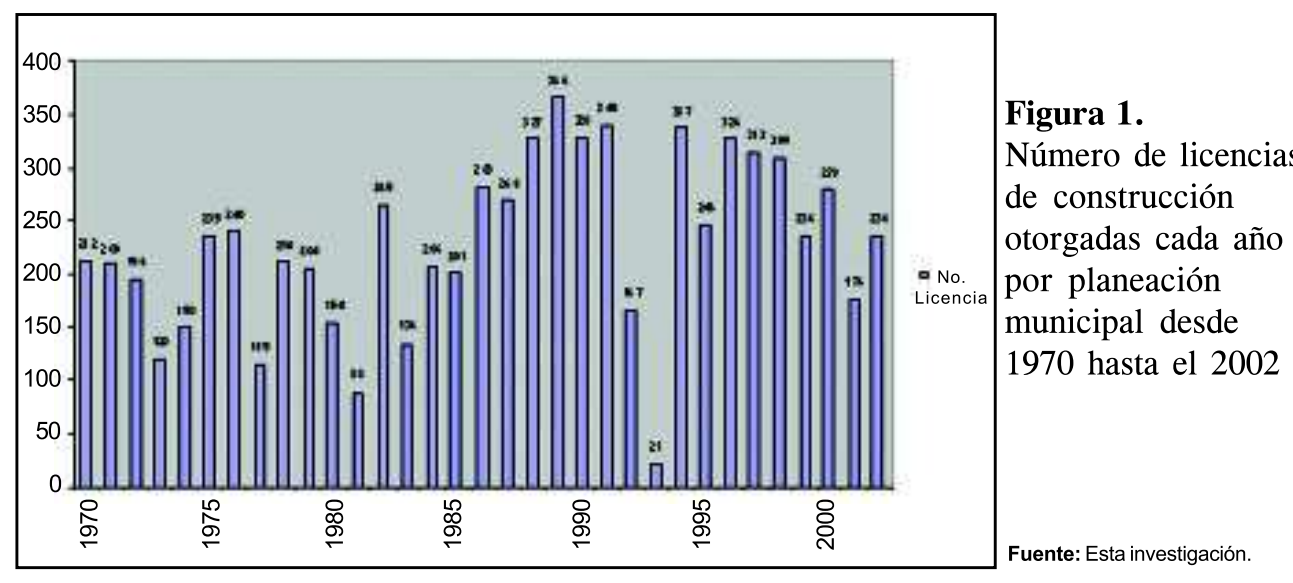

212 Guillermo Hernando Quintana Machado 
La figura expresa un aumento en el número de licencias de construcción otorgadas por la administración municipal en el año de 1989, año que pertenece al período en el cual se presenta el mayor aumento de hectáreas de área construida por año. En este sentido se puede apreciar la relación entre el área construida y el número de licencias expedidas en cada periodo.

Otro factor importante para tener en cuenta es el aumento del número de predios en el municipio (ver figura 2); esta información se obtuvo de las estadísticas catastrales suministradas por el IGAC durante el período 19702002, de las que se calculó lo siguiente: durante la década de los setenta el aumento de predios por año fue, aproximadamente, de 290, cifra que resultó ser la más baja de los períodos analizados. Como se puede observar en la siguiente gráfica, el incremento más alto se dio en la década de los ochenta, seguida por la de los noventa, con aproximadamente 489 y 409 predios por año.

\section{Figura 2. Tasa de crecimiento de los predios urbanos del municipio de Zipaquirá entre 1970 y 2002}

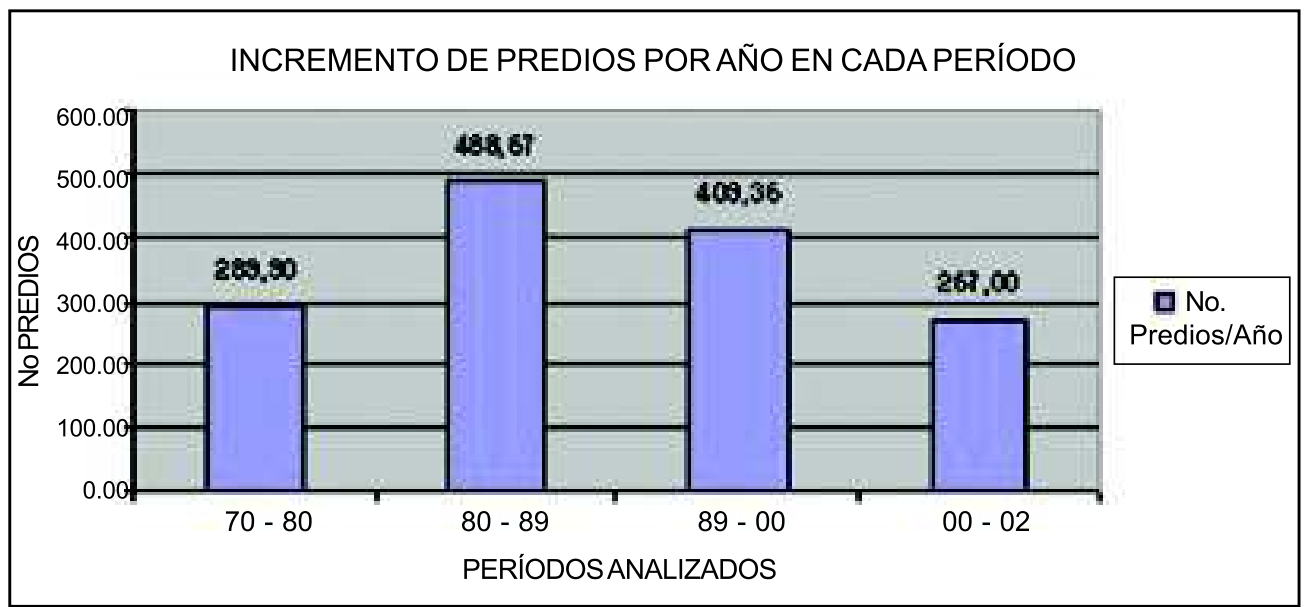

Fuente: Información IGAC, cálculos propios.

En la figura 3 se muestra el número de predios por año, para los años en que se pudo recopilar la información; se puede decir que de 1970 al 2002 el número de predios urbanos se multiplicó por cuatro, pues pasó de 4.129 a 16.463.
Por otro lado, el número de predios rurales mantuvo una tendencia de crecimiento leve hasta finales de la década de los ochenta: de 2.616 predios en el año de 1970 se pasó a 3.112 en 1989. En la década de los noventa la cantidad de predios rurales aumenta 
considerablemente, llegando a 9.503; esta fragmentación de predios rurales se debe a factores como las sucesiones de predios de gran tamaño y la presión de las áreas limítrofes al área urbana, que generan pequeños loteos para vivienda y proliferación de centros poblados rurales, entre otras consecuencias.

Figura 3.

Número de predios urbanos y rurales según reportes catastrales

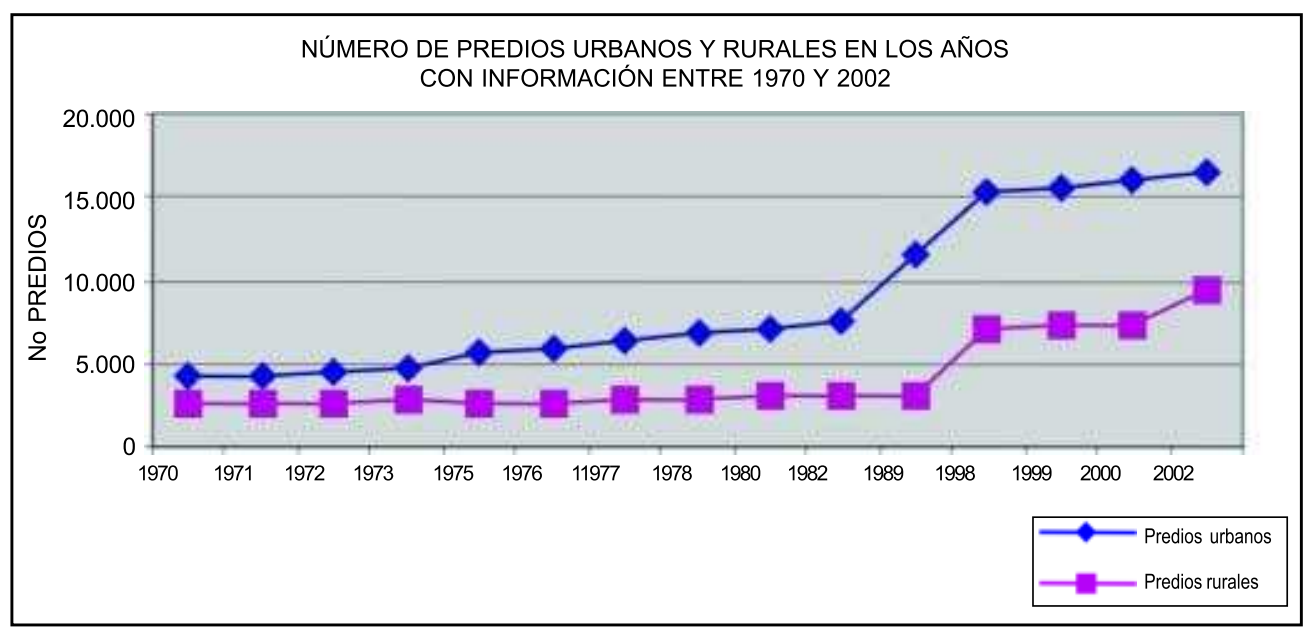

Fuente: Información IGAC, cálculos propios.

\section{La morfología urbana de Zipaquirá}

La situación de Zipaquirá es particular; está ubicada, aproximadamente, a $50 \mathrm{~km}$ de Bogotá, por la Carretera Central del Norte, y articulada con los municipios del norte de la Sabana de Bogotá por medio de vías que confluyen en forma de estrella y tienen interconexiones con la vía que conduce a Ubaté, lo cual hace de Zipaquirá un asentamiento muy accesible.

En cuanto al emplazamiento, en Zipaquirá se distinguen claramente factores físicos que condicionan el desarrollo y la forma de la zona urbana; el principal de ellos es la topografía hacia la parte oriental y nororiental, que restringe el crecimiento hacia ese sector; la infraestructura vial (carreteras y ferrocarril) también ha incidido en la actual morfología de Zipaquirá, al igual que la tenencia de la tierra, que ha sido un factor de contención o línea de fijación que ha impedido el crecimiento del área urbana compacta del municipio.

El plano de Zipaquirá inicia su evolución alrededor de una plaza central (Plaza de Los Comuneros), con un desarrollo en forma cuadricular o de

214 Guillermo Hernando Quintana Machado 
Damero, legado históricamente por los españoles en su proceso de colonización del nuevo mundo. Zipaquirá no se originó con esta morfología, fue después del traslado del lugar de fundación -denominado Pueblo Viejo- al actual emplazamiento cuando surgió la forma de damero, que hoy corresponde a la zona del centro, es en este momento cuando se da inicio al desarrollo morfológico actual del municipio.

Actualmente esa forma se conserva solamente en la zona central del Centro Histórico, por razones como la pendiente y el trazado de la vía férrea, que estructuran morfológicamente al mu- nicipio, en conjunto con las vías principales, que se construyen en forma perpendicular a la vía férrea, como por ejemplo las calles cuarta y octava, y, adicionalmente, por los mismos tipos de desarrollo urbanísticos que se dieron en el municipio en las diferentes épocas.

En el mapa 3 se observan diez clasificaciones de tipos de morfologías, trazado inicial, irregular, trazado tradicional, prebarra, barra, racimo, transición, circuito, cuña y ocupación dispersa en lotes rurales, distribuidos de la siguiente manera en la zona de estudio y con las siguientes características:

\section{Mapa 3}

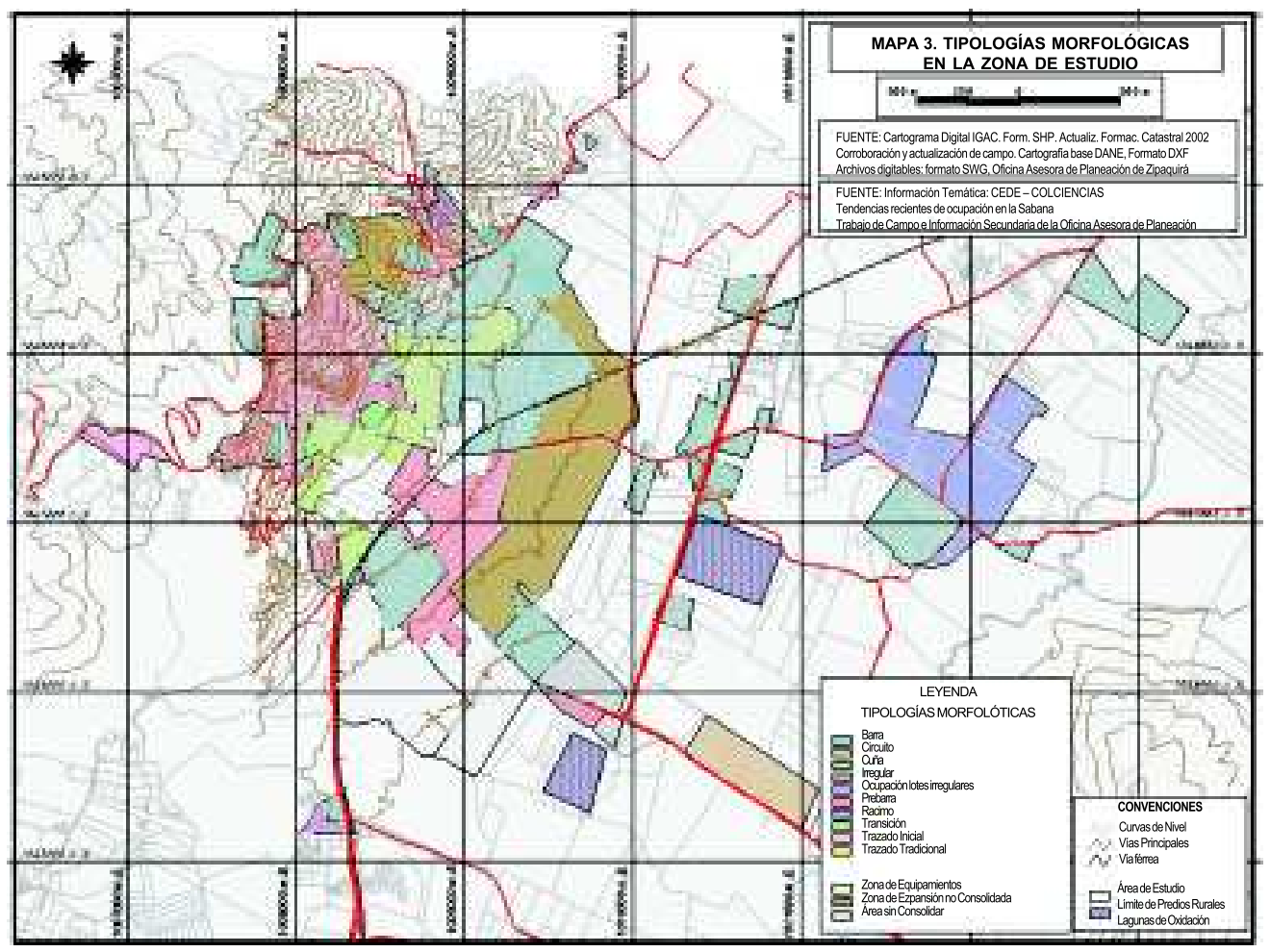


Como trazado inicial se denominó la morfología del CPR Santiago Pérez o Pueblo viejo, ubicado en la parte occidental de la zona urbana; se desarrollaron aproximadamente 8,2 ha en lotes dispuestos en doble crujía, con formas de manzanas irregulares que se enmarcan en la infraestructura vial existente.

En la parte occidental y noroccidental se presenta una tipología irregular y zonas de estratos bajos, son zonas deterioradas urbanística y funcionalmente, con desarrollos en zonas de pendientes altas; este sector, en general, se caracteriza por tener un bajo nivel de estratificación, a excepción de algunas urbanizaciones o conjuntos residenciales, que rompen un poco el continuo urbano, tratando de generar "enclaves".

La tipología morfológica que se encuentra en una mayor área del municipio de Zipaquirá es la Barra; esta forma se incrementó debido a la creciente construcción de urbanizaciones que manejan un diseño en el cual se optimiza el área del lote. Esta forma urbana se desarrolló en el municipio principalmente a partir de la década de los ochenta, según el análisis de crecimiento urbano realizado en esta investigación. En total, esta forma abarca una extensión de 264,6 ha del área de estudio, en la cual se presentan en general estratos medios y altos ubicados en la franja plana de la parte oriental de la zona de estudio.

Por otra parte, la prebarra ocupa 55,5 ha del área de estudio y está concentrada en la parte oriental, por pertenecer a estratos medios-altos; se presenta en barrios con cierta tradición residencial dentro del municipio.

La forma de racimo se presenta de manera muy aislada en la zona de Barandillas, al oriente del área de estudio; el área con esta tipología morfológica es de 88,5 ha, en esta zona se presenta gran cantidad de vivienda dispersa rural con estratos bajos y la topografía sigue siendo plana. En las últimas dos décadas esta zona se ha transformado considerablemente, porque se han incorporado aproximadamente 38,5 ha de área construida, de manera no continua, por lo tanto, pasó de ser un área eminentemente rural a Centro Poblado Rural, en la que se presentan una combinación de usos urbanos y rurales, paralelamente a esto se presenta una subdivisión de los predios por diversas causas como loteos para venta, subdivisiones por herencias, etc.

El trazado tradicional es el desarrollo en forma cuadricular o de damero, típica herencia de la cultura española, en Zipaquirá esta se evidencia alrededor de la Plaza de los Comuneros, abarcando un área de 18,8 ha y se extiende entre las carreras 15 y 11 y entre las calles 1 y 7 . Esta zona corresponde a parte del centro histórico (barrios El Centro y La Concepción), declarado patrimonio nacional por sus condiciones arquitectónicas: prevalece allí un uso comercial.

La tipología morfológica denominada de transición es la zona que rodea por

216 Guillermo Hernando Quintana Machado 
el occidente, sur y norte el trazado tradicional, es decir, comprende las manzanas que sirven de transición entre el trazado cuadricular o de damero y las formas de prebarra y barra, esta se extiende en un área de 60 ha. Con el desarrollo de esta morfología se dio continuidad al trazado tradicional y a la estructura vial del centro de la ciudad, conservando los anchos del lado de manzana tradicional, pero variando sus longitudes y acoplando los extremos no colindantes y opuestos a las manzanas tradicionales a las infraestructuras viales.

El Centro Poblado Rural Pasoancho es el único que presenta una tipología morfológica de circuito, abarca un área de 26,9 ha y se ubica sobre la vía que conduce a Tocancipá. En este CPR se encuentran lotes de diferentes tamaños; en los más grandes predominan las actividades de pastoreo y en los de menor tamaño la construcción ocupa entre el cincuenta y el ochenta por ciento del área del lote, y en ocasiones hay presencia de huertas caseras.

En la zona de estudio solamente se identificaron dos manzanas con morfología de cuñas, las dos se encuen- tran en el límite entre la morfología de transición y la irregular, en la zona donde comienza un incremento notable de la pendiente. El área que abarcan las dos cuñas es de 4,6 ha.

La Ocupación Dispersa en Lotes Rurales se refiere a construcciones dispersas en áreas predominantemente rurales, pero que por su grado de difusión, su baja densidad de ocupación y su modo de desarrollo predio a predio no llegan a ser Centros Poblados Rurales; sin embargo, para el presente análisis tienen significación en cuanto a la incorporación de área construida y su ubicación dentro de la zona de estudio. En esta categoría se encuentran algunas áreas de los CPR Argelia, Portachuelo y San Antonio, que ocupan 25,4 ha; esta forma de ocupación se genera de manera dispersa sobre las vías principales, a excepción del caso del CPR Portachuelo -en el que se dan construcciones aisladas hacia la parte occidental del área desarrollada en barras-, esta es una zona de alta pendiente donde se ocuparon lotes rurales no continuos al área consolidada, distanciados entre $100 \mathrm{y}$ $200 \mathrm{~m}$, predios que con el tiempo se incorporarán al Centro Poblado Rural (ver cuadro 4).

Cuadro 4. Tipología morfológica por barrios de la zona de estudio

\begin{tabular}{|l|c|}
\hline TIPOLOGÍA MORFOLÓGICA & ÁREA (ha) \\
\hline TRAZADO INICIAL & 8,2 \\
\hline IRREGULAR & 86,9 \\
\hline BARRA & 254,6 \\
\hline PREBARRA & 55,5 \\
\hline RACIMO & 88,5 \\
\hline TRAZADO TRADICIONAL & 18,8 \\
\hline TRANSICIÓN & 60,1 \\
\hline CIRCUITO & 26,9 \\
\hline CUÑA & 4,6 \\
\hline OCUPACIÓN DISPERSA EN LOTES RURALES & 25,4 \\
\hline
\end{tabular}


Existen áreas sin consolidar, que sin duda influyen en el continuo de la tipología morfológica urbana, como son las áreas sin construir o lotes en el interior de la zona urbana, las grandes zonas de equipamientos y las zonas de expansión. Ninguna de las anteriores obedece a una tipología de forma urbana, pero sí se deben tener en cuenta como agentes modeladores de la morfología de la ciudad; estos tres aspectos se desarrollarán más adelante en el ítem de factores físicos materiales modeladores del plano de Zipaquirá.

Análisis gráfico general de la forma y la tendencia de crecimiento de la mancha urbana del municipio de Zipaquirá

El “centro" de Zipaquirá, alrededor del cual tiene origen el trazado tradi- cional conocido como Plaza o Parque de Los Comuneros, se encuentra relativamente cerca $(300 \mathrm{~m}$, aproximadamente) de la zona de alta pendiente, cerros noroccidentales, por lo cual su expansión hacia la zona occidental y noroccidental se vio limitada. Aun así, la densidad de ocupación del sector es bastante alta; esta situación direcciona el crecimiento de la ciudad hacia el oriente (ver figura 4). Por otra parte, la ubicación de los asentamientos rurales (Centros Poblados Rurales) está relacionada con el desarrollo de la infraestructura vial, puesto que la gran mayoría de CPR tienen un acceso directo a vías intermunicipales que comunican con Nemocón, Cogua, Tocancipá y Sopó, respectivamente.

Figura 4. Tendencias y limitaciones de crecimiento de la mancha urbana

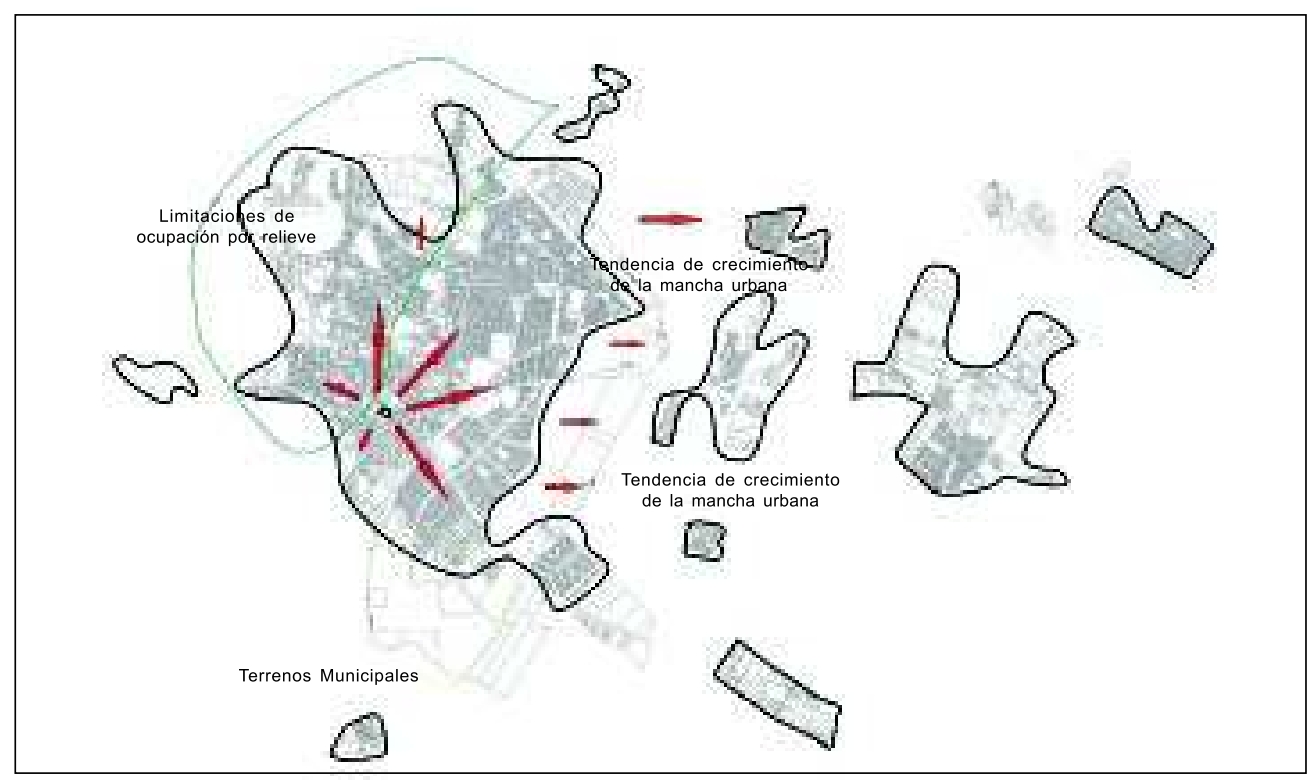

Fuente: Esta investigación.

218 Guillermo Hernando Quintana Machado 
Factores físicos materiales modeladores del plano de Zipaquirá

Relieve. Indiscutiblemente, el relieve es un determinante de la forma del plano de Zipaquirá; se puede observar que, en general, en toda la zona de estudio se hacen presentes dos paisajes claramente diferenciados por la pendiente: la parte con mayor pendiente, parte noroccidental y occidental, que presenta unas manzanas con formas irregulares y dispuestas de manera heterogénea, y la parte plana, en donde se encuentran trazados o formas homogéneas de manzanas, que se extienden hacia la parte oriental del municipio.

Infraestructuras y equipamientos. En la zona de estudio se presentan infraestructuras como las vías principales (vía férrea, calle octava, calle cuarta al oriente de la vía férrea), que modelaron en algún momento la morfología y se pueden, incluso, tomar como referentes para establecer cambios morfológicos en el área de estudio; este es el caso de la calle octava entre carreras sexta y doce, en donde a partir de esta última se rompe el tramado cuadricular y se comienzan a observar equipamientos de gran tamaño, como el parque la Floresta, el Hospital, la Salle, el terminal de transporte e inclusive la estación de policía La Floresta. Estos son equipamientos que ocupan aproximadamente una manzana cada uno, con áreas que oscilan entre alrededor de 2 ha, como es el caso del complejo que conforman el
Club Salinas, la Plazoleta Villaveces y el Colegio Eduardo Santos, hasta 57 ha en la zona de la Fragüita. Estos equipamientos tienen variadas morfologías, que van desde irregulares hasta en forma de cuña para el caso específico del Hospital. Este hecho, definitivamente, rompe con la continuidad de la ciudad, así, donde había manzanas cuadradas y rectangulares, con lados de entre $70 \mathrm{~m}$ y $100 \mathrm{~m}$ (manzana tradicional), pasan a conformarse tejidos urbanos diferentes, tanto en el centro histórico como en el resto del área compacta de estudio.

Las áreas clasificadas como zonas de grandes equipamientos, que se incluyen en el mapa de tipologías morfológicas, ocupan un área de 114,1 ha, que corresponden a un $30,73 \%$ del área compacta.

Otros equipamientos, que a largo plazo interferirán con el desarrollo de la expansión urbana y darán lugar al truncamiento o cambio de la tipología morfológica, son las Plantas de Tratamiento de Aguas Residuales (PTAR) o las lagunas de oxidación (ver mapa 1); el Plan de Ordenamiento Territorial de Zipaquirá, aprobado mediante Acuerdo 12 de 2000, contempla para estos equipamientos una franja de aislamiento de $500 \mathrm{~m}$; parte de esta área se sustrae a la actual zona de expansión urbana, planteando de esta manera una limitante de desarrollo urbano, independientemente y sin llegar a analizar la pertinencia de la ubicación de las lagunas. De mantenerse en su 
ubicación estas infraestructuras y más aún sus franjas de protección ambiental, modelarían determinantemente la tipología morfológica del futuro crecimiento urbano zipaquireño. En este sentido se han propuesto ajustes a las franjas de protección ambiental de las PTAR, en reuniones con la comunidad y la CAR.

Áreas sin consolidar. En este estudio se denominaron de esta forma los lotes o vacíos que se encontraban inmersos en el área desarrollada. En esta clasificación solamente se incluyeron los lotes de gran extensión que truncaban la continuidad morfológica de la ciudad. En esta categoría se encontraron 58,3 ha, que corresponden a un $15,56 \%$ del área compacta de estudio.

Áreas de expansión. Estas zonas son las que están previstas para el futuro desarrollo de la ciudad, por lo cual se considera pertinente su mención. Como se puede observar en el mapa 1, estas áreas ocupan un total de 138,9 ha, es decir, un $38,15 \%$ del área urbana actual.

Al realizar el análisis se encuentra que la mayoría de tierras de expansión urbana en el municipio de Zipaquirá son de grandes propietarios, y solo a partir del 2002 se han vinculado a un proceso de desarrollo urbanístico en el marco de un Plan Parcial.

\section{Estructura urbana actual de Zipaquirá}

El presente análisis retoma varios aspectos de las diferentes teorías de la estructura urbana y algunos elementos relevantes que se consideraron importantes en él. Observando la particularidad de la zona de estudio, como paso inicial se determinarán individualmente las zonas con gran importancia geográfica para el análisis, como son el sector central (Central Business District-CBD-), las zonas residenciales, comerciales e industriales (ver mapa 4).

\section{El sector central (CBD) de Zipaquirá}

El CBD, o zona "central" de Zipaquirá, tiene unas características particulares en la ciudad, puesto que presenta gran intensidad en la actividad comercial, tiene una amplia gama de establecimientos recreativos, de entidades financieras y de servicios; son estos usos los que predominan en este sector de la ciudad, que se encuentra ubicado hacia el occidente del área urbana compacta o de desarrollo continuo de la zona de estudio. El alto grado de especialización del sector comercio en la zona atrae poblaciones del municipio y de sus vecinos, lo que incrementa en gran medida el flujo vehicular. 


\section{Mapa 4}

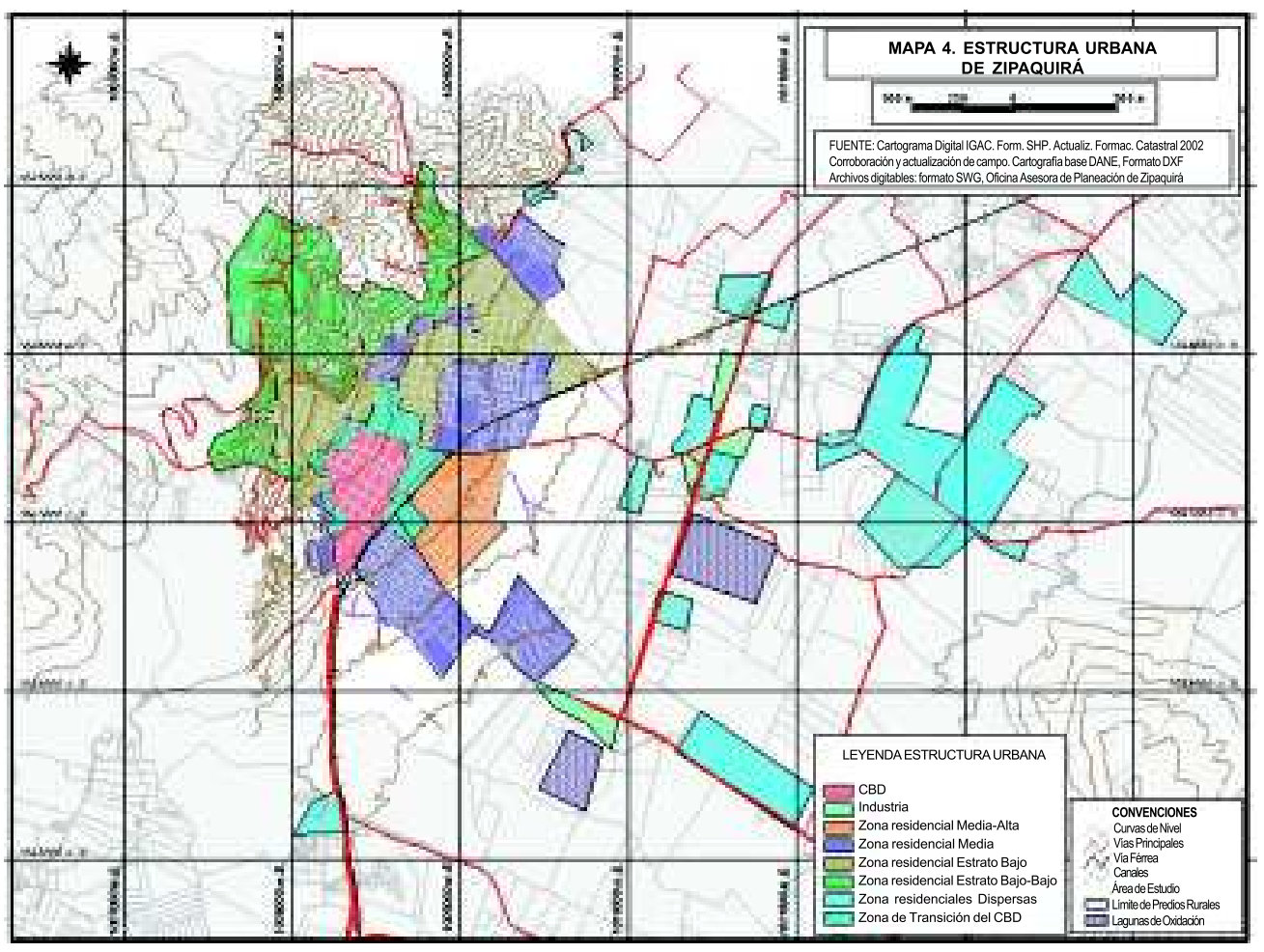

La zona del Central Business District tiene buena accesibilidad; a nivel intramunicipal tiene fácil comunicación con todos los otros sectores del municipio -entre quince y veinte minutos en transporte público la separan de los puntos más alejados de la zona de estudio-. A nivel intermunicipal, con el CBD se conectan todas las vías que vinculan a Zipaquirá con municipios vecinos, como Cajicá, Cogua, Sopó, Ubaté, Pacho, Tabio, Nemocón y Tocancipá.
Sin duda alguna, uno de los factores que caracterizan el CBD es el elevado valor del suelo, que de una u otra forma está ligado a la intensa actividad económica de la zona y a los niveles de especialización del uso de su suelo.

En gran número de ciudades el CBD se caracteriza por una alta concentración de edificios altos, lo cual no se aplica al caso zipaquireño. La zona céntrica de Zipaquirá se caracteriza, de manera general, por no superar los 
tres pisos de altura (predominan dos pisos). En este sentido es pertinente aclarar que parte del barrio El Centro, exactamente $555.111,53 \mathrm{~m}^{2}$ (57 manzanas), fue declarada patrimonio nacional por Colcultura (ahora Ministerio de Cultura); este hecho implica unas restricciones o condicionamientos al desarrollo urbanístico de la zona y, por tanto, a los desarrollos en altura que rompan el continuo de la arquitectura de tipo colonial que presenta el área. Es esencialmente por esta causa que el CBD de Zipaquirá no se caracteriza por edificios altos y que la ciudad se vio obligada a crecer horizontalmente con más intensidad que otros pueblos.

El CBD de Zipaquirá tiene gran dinamismo; en la década de los setenta, en su gran mayoría, se dedicaba al uso residencial y comercial, con predominio del primero. Los desarrollos urbanos de las décadas posteriores, de los ochenta y noventa, presionaron el desplazamiento de la actividad residencial a barrios construidos exclusivamente para este uso. Por otra parte, el comercio minoritario acaparaba la zona central y se iba desarrollando gradualmente la especialización de algunos usos específicos, que contribuyen hoy a hacer del municipio un polo de desarrollo subregional, con énfasis en la prestación de servicios.

El CBD zipaquireño se extiende desde la calle primera hasta la octava, entre las carreras quinta y once. El centro de negocios coincide espacialmente con gran parte del suelo de mayor valor, lo que ratifica la estrecha relación que existe para el área de estudio entre las variables valor del suelo y actividad económica.

\section{Las zonas de transición}

El límite del CBD no es una línea fija o un punto de quiebre brusco en la ocurrencia de los usos del suelo urbano, que signifique una distinción clara entre el centro de negocios y su entorno; por el contrario, la difuminación de los usos centrales de manera gradual es lo que dificulta, en la mayoría de los casos, su delimitación. En Zipaquirá, el sector central se encuentra rodeado por manzanas consideradas de transición, en sus costados occidental, norte y oriental; hacia el costado sur no hay zona de transición, simplemente la continuidad del uso se trunca al encontrar la vía férrea y la calle primera.

\section{El espacio residencial}

Las zonas residenciales presentan múltiples matices. Se encuentran en la zona de estudio tipificaciones de áreas dedicadas a vivienda de estrato medioalto, como el sector de los barrios Algarra I, II y III, y sectores con destinación para viviendas estratificadas en I y II, como el sector noroccidental y sus alrededores, áreas con mayor pendiente y forma urbana irregular.

Las zonas residenciales de estratos medio y medio-alto se localizan principalmente al oriente y nororiente del 
CBD, en donde los precios del suelo oscilan entre $\$ 75.000$, oo y $\$ 90.000$, oo el metro cuadrado; por otra parte, las zonas residenciales de estratos bajos se localizan al occidente y noroccidente del centro de negocios, y el precio por metro cuadrado puede oscilar entre $\$ 2.200$,oo y $\$ 11.000$,oo.

Otros espacios de tipo residencial que caracterizan la zona de estudio son los desarrollos a saltos, o dispersos, tipificados en algunos casos como centros poblados rurales y en otros como zonas urbanas no continuas, que se distinguen por ser de estratos bajos y muy bajos; dichos asentamientos están ligados funcionalmente a ejes viales principales que comunican con otros municipios y con el CBD.

\section{El espacio no residencial}

\section{Áreas comerciales}

La presencia de actividad comercial por fuera del CBD es esporádica; se presenta comercio al por menor combinado con actividad residencial e institucional. Por otro lado, es pertinente destacar el proceso de consolidación comercial que se está dando en algunos ejes viales como la carrera décima al norte de la calle octava y, a menor escala, la carrera diecinueve y la calle diecisiete.

\section{Áreas industriales}

La ubicación de las áreas industriales en la zona de estudio obedece a la variable de accesibilidad, identificándose dos zonas con asentamiento de industrias medianas: una sobre la calle cuarta, vía a Pasoancho antes de la intersección con la carrera 36 (vía a Ubaté), y la otra sobre la carrera 36 en la intersección con la calle octava, barrio La Paz. Estas dos zonas tienen fácil acceso y amplia posibilidad de transporte de materias primas y distribución de productos vía Briceño-Bogotá o Ubaté-Chiquinquirá-Barbosa. En proporción con el tamaño de Zipaquirá y el papel regional del municipio, la actividad industrial no está desarrollada.

\section{Conclusiones}

El crecimiento urbano de Zipaquirá se realizó de manera compacta hasta finales de la década de los setenta; en la década de los ochenta se presentaron desarrollos a saltos de rana, distanciados del área urbana compacta hasta cuatro kilómetros; estos son denominados centros poblados rurales y se caracterizan por tener un bajo nivel socioeconómico y una consecuente deficiencia en los servicios públicos y sociales.

El período en el que hubo un mayor crecimiento del área urbana consolidada fue entre los años 1997 y 2002, cuando aumentó casi 100 hectáreas por año; por otro lado, el menor crecimiento se dio en la década de los setenta, cuando el municipio de Zipaquirá estaba apenas empezando una fuerte dinámica urbana. 
Al evaluar la morfología urbana de Zipaquirá se puede decir que en la zona de desarrollo continuo, o área compacta de estudio, el mayor porcentaje lo ocupan las tipologías morfológicas de barra y prebarra, lo cual implica, por las características de este tipo de formas (trazado regular), la existencia de un buen urbanismo, como efectivamente lo presentan los barrios que tienen esta clase de desarrollos. Adicionalmente, se puede agregar que estas áreas son las que tienen un valor alto del suelo y coinciden con las de mayores estratos socioeconómicos en el área urbana compacta, lo cual podría implicar una relación directa entre tipología y estrato socioeconómico para esta área específica. Situación contraria ocurre en la zona dispersa, donde, aun teniendo tipologías de barra y prebarra, predominan los estratos bajos, es el caso de los desarrollos en Barandillas y San Miguel.

Esta relación entre tipología y estrato también se podría establecer en los sectores con trazado tipológico irregular en la zona de estudio, ubicados en las áreas con alta pendiente, al norte del centro histórico. En los barrios de este sector predominan los estratos socioeconómicos uno y dos, con algunas excepciones de desarrollos urbanísticos en barra, que se encuentran también en zonas de alta pendiente y tienen estrato medio.

El centro de negocios, CBD, presenta una baja altura por efecto de la normativa de declaratoria de patrimo- nio. El municipio de Zipaquirá se caracteriza por tener una zona urbana compacta, que se denominó en este artículo zona de desarrollo continuo.

Por otra parte, la forma actual de la mancha urbana, que se asemeja a una media luna o semicírculo, se debe, por el oriente, a factores físicos como la pendiente, que limita la expansión hacia el oriente y nororiente, y la vía férrea, que es un eje estructurante marcador de forma.

La zona de estudio tiene una única centralidad o CBD, que coincide con el centro tradicional, en el cual predomina la tipología morfológica de manzana tradicional y hay una intensa actividad en los usos del suelo urbano, en la que predominan el comercio al por menor y los servicios.

A principios de los años setenta este centro era principalmente residencial y mixto, pero la concentración de actividad económica y la dinámica de los precios del suelo llevaron a un desplazamiento de la actividad residencial hacia la periferia del centro. Con esto las actividades de tipo económico se consolidaron con el paso de los años, hasta establecer la configuración actual del centro de negocios.

En Zipaquirá, la estructura urbana muestra cierta diferenciación territorial de funciones, como son las zonas de estratos bajos y las zonas residenciales de estratos medios, que se especializan en sectores específicos del municipio.

224 Guillermo Hernando Quintana Machado 
En cuanto a las zonas de transición, que son áreas periféricas al CBD, predominan los usos mixtos, comercio, servicios y actividad residencial; es muy probable que estas zonas sean absorbidas por el centro de negocios, al observar con los años el incremen- to de los usos propios de la zona central. En la zona de estudio, las actividades del CBD se van extendiendo sobre los ejes viales principales, lo cual muestra relación entre el valor del suelo y las actividades del CBD.

\section{Bibliografía}

Alcaldía Municipal de Zipaquirá (1999): Plan de Ordenamiento Territorial Municipal, Oficina de Planeación Municipal, Alcaldía Municipal. Anexo D.

BorJa, J. y M. Castells (1997): Local y global, La gestión de las ciudades en la era de la información. Madrid: Grupo Santillana de Ediciones S.A.

BARRoss, Claudia (1999): "De rural a urbano: transformaciones territoriales y construcción de lugares al sudoeste del área metropolitana de Buenos Aires. Scripta Nova, Revista Electrónica de Geografía y Ciencias Sociales 45(51) [1 de agosto]. Universidad de Barcelona.

BRACCO, Sergio (1988): Los sistemas metropolitanos de las nuevas ciudades. Barcelona: Oikos-tau.

CARTER, Harold (1972): El estudio de la geografía urbana. Londres: Edward Arnold Ltda.

CARvajal, Guillermo (1985): "El proceso de urbanización en la periferia del área metropolitana: los casos de Turrucares y Monte de la Cruz". Revista Geográfica de América Central Núms. 17-18. Heredia (Costa Rica): Universidad Nacional Autónoma.

Castells, Manuel (1973): Imperialismo y urbanización en América Latina. Barcelona: Editorial Gustavo Gili.

(1982): La cuestión urbana. México: Siglo Veintiuno editores.

Corporación Centro Regional de Población (1973): América Latina: Distribución espacial de la población. Ramiro Cardona (Ed.), Sochagota.

Colciencias-Cede (1999): Tendencias recientes de ocupación territorial en Bogotá y la región. Universidad de los Andes, convenio Gobernación de Cundinamarca.

Del Canto, F., S. Carreras, P. Gutiérrez, Del V. Gutiérrez, S. Pérez (1993): Trabajos prácticos de geografía humana. Madrid: Síntesis. 
Durán A., César (1972): "Introducción a la geografía urbana”. Revista Geográfica Núm. 8 [Dic.], Instituto Geográfico Militar.

EstéBAnez, José y otros (1995): Geografía Humana, Madrid: Cátedra.

Gómez, Delio (1990): Morfología urbana o el significado de las formas urbanas (Ensayo sobre la historia de las formas urbanas), Bogotá: Universidad Piloto.

GreÑas M., Rosa (1982): "Un caso de suburbanización en la aglomeración metropolitana”. Revista Geográfica de América Central Núms. 9-10. Heredia: Universidad Nacional Autónoma.

HERnÁNDEZ SAMPIERI, Roberto (1995): Metodología de la investigación. Bogotá: McGrawHill.

IgAC (1990): "Proceso de urbanización en Colombia". Análisis geográficos Núm. 15. Bogotá: IGAC.

Knox P., S. Pinch (2000): Urban Social Geography, An introduction. England: Pearson education Limited.

Misión Siglo XXI (1995): El futuro de la capital. Estudio prospectivo de las relaciones de Santa Fe de Bogotá con Cundinamarca. Bogotá: ELC.

Montañez, Gustavo, SENA y Universidad Nacional de Colombia (1994): ¿Hacia dónde va la Sabana de Bogotá? Modernización, conflicto, ambiente y sociedad. Bogotá: SENA-UN.

Rodríguez S., Raúl H (1989): Urbanización de Florencia, análisis socio-espacial urbano regional. Bogotá: IGAC, UPTC.

TuRKSTRA, J. (1998): Urban development and geographical information: Spatial and temporal patterns of urban development and land values using integrated geo-data, Villavicencio (Colombia): ITC Publications Series Núm. 60.

Universidad Externado de Colombia (2001): Ciudad y región en Colombia, nueve ensayos de análisis socioeconómico y espacial. Bogotá: Óscar A. Alfonso.

Vinuesa A., D. Vidal (1991): Los procesos de urbanización. Madrid: Síntesis.

ZÁrate, Antonio (1992): El mosaico urbano. Organización interna y vida en las ciudades. Madrid: Cincel Kapelusz.

Fecha de recepción: junio de 2004

Fecha de aprobación: agosto de 2004

226 Guillermo Hernando Quintana Machado 